\title{
A Brief Review to Study of Rice Mill Water Pollution on Mahanadi River at Chhattisgarh
}

\author{
Shilpi Shrivastava and Sushma Sharma* \\ Department of Chemistry, Kalinga University, Atal Nagar, Nawa Raipur Chhattisgarh, India
}

\begin{abstract}
The process of parboil, involves soaking, steaming and drying and this requires large amount of water for soaking the paddy. The soak water contains high load of suspended and dissolved organic materials which putrefies overtime causing water and groundwater pollution. The groundwater is polluted due to release of waste water from rice mills of this area. Various water quality parameters were characterized such as turbidity; Acidity, Biochemical oxygen demand (BOD), Dissolved Oxygen (D0) chemical oxygen demand (COD) Iron, Hardness, Chloride, and Sulphate were studied. It has been found that the parameters such as Iron, B.O.D., D.O. and C.O.D., are not in the acceptable limit in accordance with the IS 10500 (2012) drinking Water Quality Standards. The current study will mainly focus on the effect of rice mills on groundwater at Mahanadi River near Rajim.
\end{abstract}

Keywords: Rice mill, Waste water Rajim region.

\section{INTRODUCTION}

Rice processing industry is the biggest industry in various districts of Chhattisgarh. The basic principle of the rice milling process is to remove the unwanted elements in paddy and involves hot water treatment of paddy after 5-6 hours the waste water is discharged from the rice mill discharged water which carries a high quantity of dissolved organic matter is the primary source of water pollution (1).

\section{MILLING AND PROCESSING}

First of all the raw rice collected from the area is firstly clear by raw rice cleaner to isolate the degradation the raw rice is dip in water 9-10 hours and switch striate to the boiling tank. And mist from the big boiler is put to the boiler tank for 30-35 minutes the tank field and familiar salt are mix as add-on to conduct the varnish of paddy and to cut off the boiling point each to each. Boiler can be uses outdate as fuel and water from the above tank to bring about condensation. After that primary boiling of raw rice, it generates water in boiler from the above tank. The rice is kept in water for 10 hours, after that water is drained and again 30-35 minute steam after second process the rice is dry by the drier. Then rice is kept for 10 to 12 hours to dry by the sunlight. People also used other drier for example mechanical drier can be use skin as its power. After that the paddy is ready to the milling from the mil entry. Firstly paddy is cleaned by the mill entry and put down the rubber eraser puzzler for milling then milling it is move through a husk to separate by the aspirator. Then unpolished rice move through the metal polisher after that corn is isolated and polished paddy rice next move to the rice grader and broken rice it's also separated and later then shield in other packets. Lastly the seal packing is ready for marketing. Average 70 kilos rice and 4 kilos broken rice are released. The bran is useful to the oil mills for oil extraction and husk is necessary to drying for boiling of the rice mill. Water is also important during the operation and processing of raw paddy.

\footnotetext{
*Address of Correspondence: Department of Chemistry, Kalinga University, Atal Nagar, Nawa Raipur Chhattisgarh, India.

E-mail-sushmasharmarajim@gmail.com

(Received 21 October 2020; Revised 07 November 2020; Accepted 11 November 2020)
} 


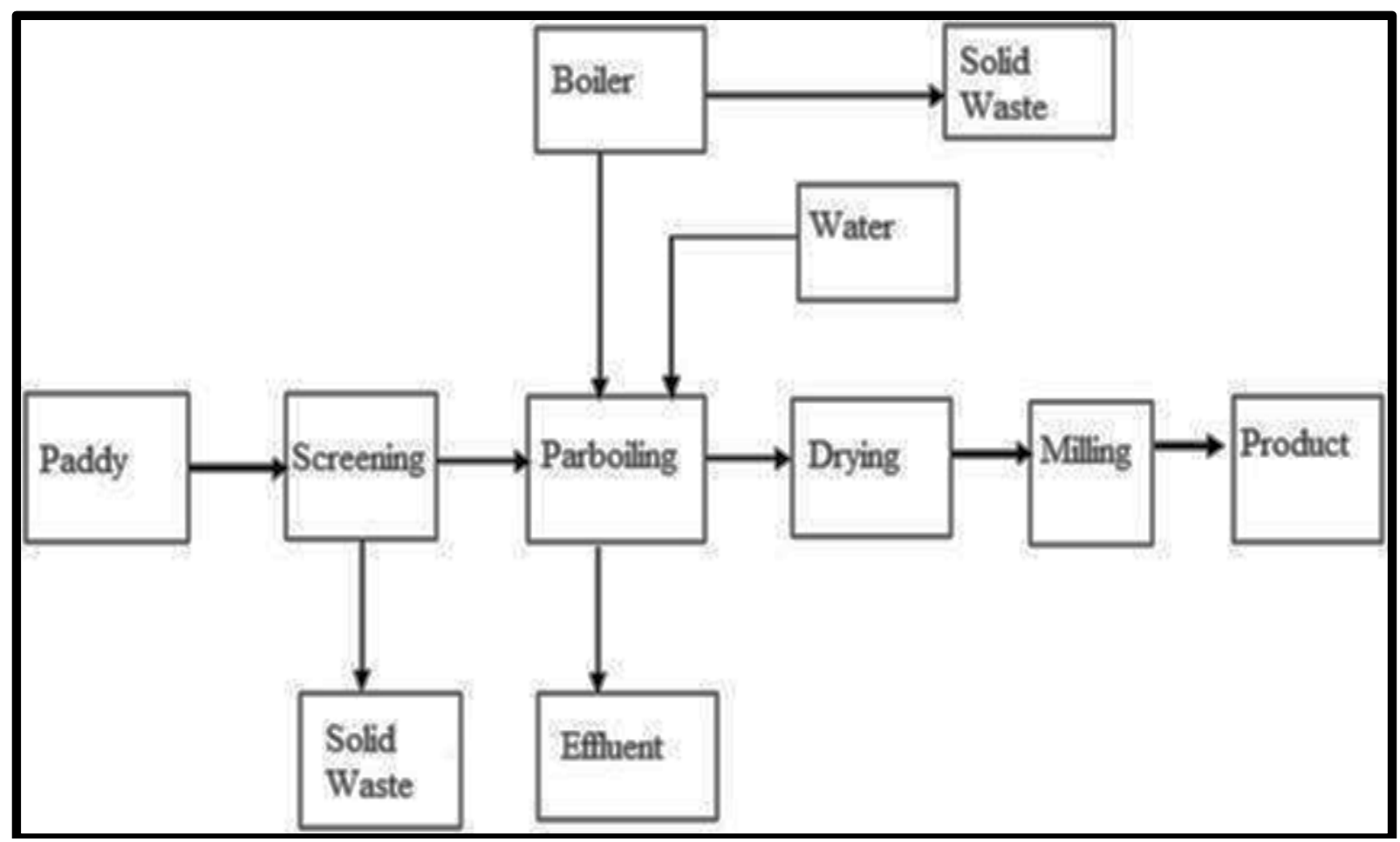

Figure 1: Diagrammatic presentation for the processof parboiled rice production and source of wastewater

\section{CONSIDERATIONS}

The treatment of water generated by industry remains a significant environmental pollution issue because of its huge quantity and its diversity. Mainly there are major of a three to four factors which are (1) domestic and industrial effluent wastes (2) Pesticides and fertilizers (3) agriculture and livestock (4) rubbish and faecal water dumping.

In this process which is the global optimal solution or maximizing COD and Total Soluble Solids (TSS) removal with minimum electrifying energy from rice industry its continuously electro coagulation treatment technique the optimum variables were found to be initial $\mathrm{pH}$ (2), Anaerobic fixed film fixed bed bioreactor has enormous potential for stabilization of parboiled rice manufacturing reduction in 84.0$93.6 \%$ and $81.2-85.0 \%$ respectively, hence from the comparative results it can be concluded that for the treatment of parboiled rice manufacturing wastewater bio Pac media is more efficient than. Mainly media matrix are fixed synthetic wastewater treatment using algal has been done with varying conditions and it was optimized. Natural pH-7 combination of algae with aeration,50g algal dosages was carried out and removal of $53.11 \%$ TDS mainly turbidity, $78.70 \%$ BOD,54.96\%, COD 46.11\% ammonia nitrogen, 76.32 phosphate were obtained since some of the parameter are not within the annual limit $(3,4)$. Post treatment has to be provided mainly objective is to provide are view of the characteristics of every possible thing. Parboiling causes a gelatinization of the starch during boiling and the cooling analyze and re-associate with each other and form a lightly packed structure, having melting temperature much higher than $100^{\circ} \mathrm{C}$ have an impact on the texture properties of the cooked parboiled rice $(5,6)$. The parboiling process moves micro nutrients contained in the barn is normally remo ved, parboiled generally required huge amount of water for soaking of the paddy. Salinity and total dissolved solids still pose an economical problem from the industries (7). These have been employed as major and fast parameters, the characterization of waste water shows that water is highly biodegradable as is seen from COD/BOD ratio+. 


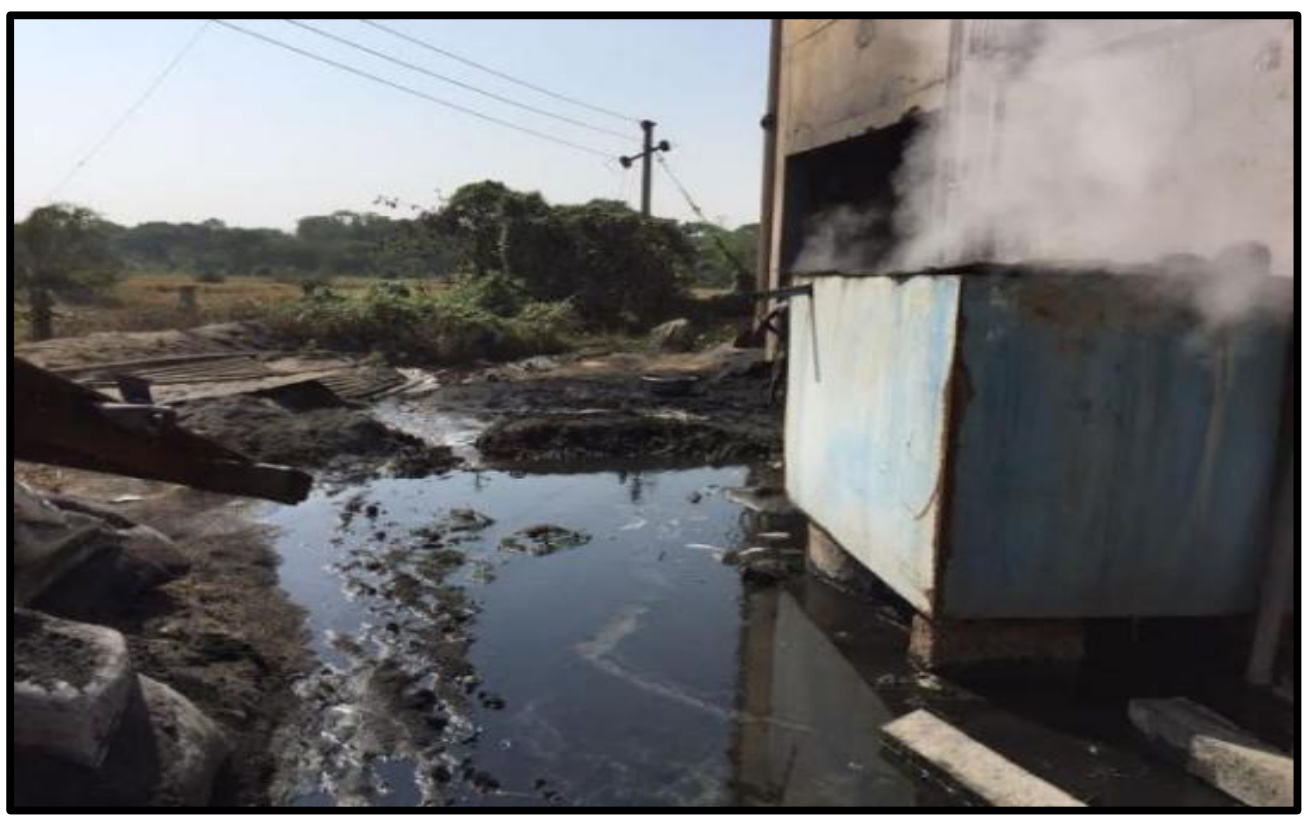

Figure 2: Waste water after Parboiling process

In the above process iron and aluminum have been used for electrodes, besides steel and other metals have been used (8). Every electrode dissolve at anode and produce metal hydroxide which from large complexes with the every pollutant and pollutions (9). Other hand rice mill is $100 \%$ replacement for portable water to paddy the power of the concert replacement of rice mill waste water provides the additional environmental and technical benefits for old related industries. The present study concluded than the higher concentration of effluents exert more stress on the germination potential of rice plant 50 the lower concentration of rice mill effluent can be amended with the soil not only to gain better yield of crops but also to reduce disposal problems relating to rice mill effluent. Even though the rice mills discharge waste water after treatment which is not so effective and they need to go for better treatment before and after disposal. So to draw a better conclusion, a long term study to get a broad and clear picture of the alkalinity, $\mathrm{pH}$ and total hardness, D.O., T.D.S. and TS for all samples are require (10).

\section{CONFLICT OF INTEREST}

There is no conflict of interest in this present study. This research work is not a part of any other studies and it is our original work.

\section{REFERENCES}

1. Rashmi Sharma. Water Pollution Studies with Special Reference to Ajmer Rajasthan India. Eart \& Envi Scie Res \& Rev. 2019; 2(1): 1-4.

2. Muhammad Musaa Khan, Yi Yang, Islam-ud-Din. Impacts of Sugar mill's Effluent on soil and Plant's Seed Germination, Punjab, Pakistan. Journal of Earth Sciences \& Environmental Studies. 2019; 4(3): 623-637.

3. Malaya R Mahananda, Priyadarshini N Sahu and Prabhati Seth. Effect of rice mill effluent on growth and biochemical parameters of Lycopersicon esculentum in pot culture. Int. J. Pure App. Biosci. 2015; 3(6): 192-203.

4. Asati SR. Treatment of Waste Water from Parboiled Rice Mill Unit by Coagulation/Flocculation. Int. J. Life Sc. Bt \& Pharm. Res. 2013; 2(3): 264-277.

5. Agarwal R, Agarwal SK. Pollutional effect of sugar factory effluents on seed germination and seedling growth of Cyamopsis tetragonoloba (Linn.) Taub., Indian J. Applied and Pure Biol. 1990; 6(1):13-16.

6. Srivastava N, Sahai R. Ecophysiological response of certain crop plants of Eastern Uttar Pradesh to industrial effluents. Int. J. Ecol. Environ. Sci. 1988; 14: 229-248.

7. Lenntech water treatment and air purification (2004) water treatment. Lenntech rotter damseweg Netherlands.

8. Vani Sharma and Padma Singh. Heavy metals pollution and its effect on environment and human health. 2015; International Journal of Recent Scientific Research. 6(12): 7752-7755.

9. Cregg James $M$ and David $R$ Higgins. Pichia Protocols. Totowa (N.J.): Humana press, 1998.

10. Sundaram R. Studies on the nitrogen nutrion of rice plants Ph.D thesis, University of Madras, (1980). 